\title{
Nurses and the Manchester: rearranging the work process and emergency care?
}

\author{
Os enfermeiros e o Manchester: reconfiguração do processo de trabalho e do cuidado em emergência? \\ Enfermeras y Manchester: ¿reconfigurando el proceso de trabajo y la atención de emergencia?
}

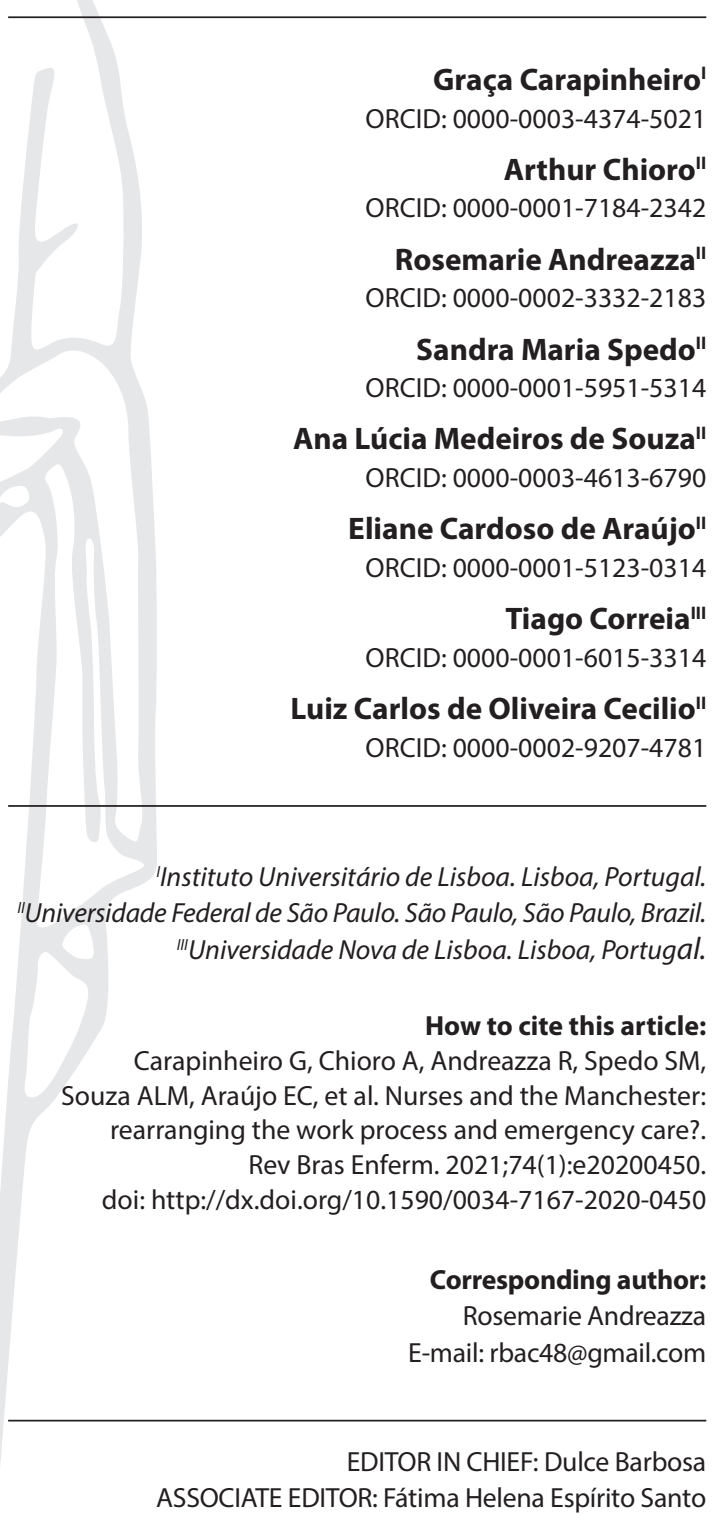

Submission: $07-08-2020$

Approval: 09-17-2020

\begin{abstract}
Objectives: to understand the changing roles of nurses in labor division organization in hospitals from the Manchester Triage System implementation in an emergency hospital. Methods: this is an ethnographic study that used different production techniques and data analysis. Results: the Manchester Triage System organized flows and places resulting in quality of care and changes in work processes. Conflict relationships related to disagreements in risk stratification were present. Final Considerations: the traditional roles of nurses have been transformed, but it cannot be said that there was a structural change in their position in labor division organization in hospitals. The frontiers of autonomy, therefore of increasing the professionalization of nurses, are neither fixed nor stable, expanding or contracting according to the micropolitical changes in the governance of care.

Descriptors: Emergency Medical Services; Emergency Nursing; Nursing Care; Triage; Patient Care Management.
\end{abstract}

\section{RESUMO}

Objetivos: compreender as mudanças de papéis dos enfermeiros na organização da divisão do trabalho no hospital a partir da implantação do Sistema Manchester de Classificação de Risco em hospital de urgência e emergência. Métodos: estudo etnográfico, com o emprego de diferentes técnicas de produção e de análise de dados. Resultados: o Sistema Manchester de Classificação de Risco organizou os fluxos e lugares, resultando em qualidade do cuidado e em mudanças nos processos de trabalho. Relações de conflito relacionadas às discordâncias na classificação do risco estiveram presentes. Considerações Finais: os papéis tradicionais dos enfermeiros se transformaram, mas não se pode afirmar que houve mudança estrutural da posição deles na organização da divisão do trabalho no hospital. As fronteiras da autonomia, portanto de aumento de profissionalização dos enfermeiros, não são fixas nem estáveis, alargando ou contraindo de acordo com as mudanças micropolíticas da governabilidade do cuidado.

Descritores: Serviços Médicos de Emergência; Enfermagem em Emergência; Cuidados de Enfermagem; Triagem; Administração dos Cuidados ao Paciente.

\section{RESUMEN}

Objetivos: comprender los roles cambiantes de las enfermeras en la organización de la división del trabajo en el hospital desde la implementación del Sistema de Triaje Manchester en un hospital de urgencia y emergencia. Métodos: estudio etnográfico, utilizando diferentes técnicas de producción y análisis de datos. Resultados: el Sistema de Triaje Manchester organizó flujos y lugares, lo que resultó en calidad de atención y cambios en los procesos de trabajo. Estuvieron presentes relaciones conflictivas relacionadas con desacuerdos en la clasificación del riesgo. Consideraciones Finales: los roles tradicionales de las enfermeras se han transformado, pero no se puede decir que hubo un cambio estructural en su posición en la organización de la división del trabajo en el hospital. Las fronteras de la autonomía, por tanto de incrementar la profesionalización del enfermero, no son fijas ni estables, ampliándose o contrayéndose según los cambios micropolíticos en la gobernanza del cuidado.

Descriptores: Servicios Médicos de Urgencia; Enfermería de Urgencia; Atención de Enfermería; Triaje; Manejo de Atención al Paciente. 


\section{INTRODUCTION}

Implementing measures aimed at reorganizing patient inflow into emergency services has been a guide for emergency services. The Manchester Triage System (MTS) represents one of these care devices by clinical priority. MTS aims to identify and prioritize clinical care in a timely and resolving time, as opposed to that performed on a first-come, first-served basis ${ }^{(1)}$. Nurses stratify risk through algorithms that allow individuals who require immediate care to be assisted first, followed by those who appear to be of clinical severity and lower level of suffering ${ }^{(2)}$.

This technological arrangement, created and initially implemented in the city of Manchester, in 2000, was quickly incorporated in several countries, including Brazil. A recently published article on MTS implementation in a municipal emergency network of the Unified Health System (SUS - Sistema Único de Saúde) clarifies the basic processes of its operation, which includes components of control, audit and continuing education by management ${ }^{(2)}$.

Concisely, this arrangement stratifies the severity of complaints and symptoms of users using pre-defined protocols for 52 clinical conditions. This severity, linked to risk, obeys a color scale that ultimately defines the order of care and patient flow ${ }^{(3)}$. Despite this, stratification does not always work as an effective filter to quickly define a diagnosis and, therefore, the follow-up of complex and critical clinical conditions. Other factors end up influencing, redesigning MTS protocolization, which can originate intense variations of risk stratification and consequent intervention strategies, according to the greater or lesser contingency and unpredictability of users' clinical situations.

The international scientific literature highlights the role of nurse practitioners in emergency services ${ }^{(4-6)}$, indicating that this action can improve access, decrease capacity, improve quality of care, decrease length of stay and increase patient satisfaction. It also emphasizes the strategic position of nurses in MTS operationalization, whether in stratification rooms designed to regulate entry flow and prioritize care ${ }^{(6)}$, or in the internal flow organization of work processes.

These two aspects, when placed in a plan of MTS operationalization, raise relevant questions for analysis: to what extent is there a change in the professional roles of nurses? Do they cause structural or just functional changes, adding dimensions in the practice of nurses who respond effectively to time pressure, which trigger greater fluidity in care flows? The so-called strategic position of nurses in MTS operationalization can also correspond to the emergence of gains in control, creation and freedom over their practices, with gains in increasing professionalization dimensions. On the other hand, in MTS, physicians' positions of power, whether in management positions and auditors of the system itself, or as clinicians in the emergency hospital space itself, can impose limits on the extension of this autonomy, namely with regard to the decision conduct of the clinical cases; however, the new position of nurses may create new types of conflict in the relationship between nursing and medicine.

This article will address the professional autonomy of nurses in an emergency hospital (EH) as one of the dimensions of professionalism, from the two analytical plans intrinsically linked, from the implementation of a new techno-assistance model of reception and risk stratification through protocolization of clinical signs and symptoms, which qualifies, order and regulates user flow at the emergency service entrance. The first is related to changes in nursing practices and changes in work processes based on this new organizational reorganization of EH, i.e., flows and places of care. The second seeks an approximation with the changes in the position and roles of nursing in labor division and conflict relations.

\section{OBJECTIVES}

To understand the changes in the roles and position of nursing in labor division organization in hospitals, which may have been triggered by the Manchester Triage System implementation in an emergency hospital service.

\section{METHODS}

\section{Ethical aspects}

This article is part of a larger investigation that had as main objective to understand how care management arrangements in emergency services are operationalized by professionals ${ }^{(7)}$. Therefore, the ethical aspects of maintaining confidentiality, agreement on the risks involved in methodological procedures and guaranteeing non-individualized treatment were respected. All participants signed the Informed Consent Form. The research project was approved by the Research Ethics Committee linked to the National Research Ethics Committee of the Brazilian National Health Council (Conselho Nacional de Saúde).

\section{Theoretical-methodological framework}

With the intention of getting closer to the world of work and care, understanding how it is meant and built by the people who inhabit it, it is inevitable to take the path of ethnography, which is understood as:

[...] a field research activity, for extended periods of time, with direct contact with the object of study, followed by systematization in text format of the experience [...] it is an activity during which knowledge is being built theory together with data collection. Thus, it is not only a research method, but a process conducted with a reflexive sensitivity, taking into account the experience in the field with the people with whom the anthropologist works. [...] the work [...] consists of looking, listening and writing. [...] this experience is only ensured by participant observation ${ }^{(8)}$.

In line with the purpose of this article and the methodological framework for analyzing the findings, the sociology of the professions' authors will be used ${ }^{(9-10)}$.

\section{Type of study}

An ethnographic investigation was carried out ${ }^{(11)}$. SRQR (Standards for Reporting Qualitative Research) was used to describe the methodology of this article. 


\section{Methodological procedures}

The methodological strategies adopted were translated into the prolonged and continued presence of researchers in the field to observe the daily operation of MTS by nurses in different rooms and times. Field visits were prepared for each visit to the service. This option resulted in an approach to the micropolitics of MTS management and to patient access times regulation for the production of care $^{(7)}$, assuming that these processes are redefined and redesigned as they are used by the actors involved in their execution and management.

The systematization of the findings was presented in three large blocks, described below in the data collection and organization sub-item, being presented in seminars shared between researchers, managers and coordinators responsible for $\mathrm{EH}$. In addition to validating the findings from a first return of results, new empirical elements were collected. Thus, a new round of seminars was held, now with professional bodies. In the case of this article, seminars with nurses were used. Chart 1 describes the different data production techniques used.

Chart 1 - Description of the research techniques used

\begin{tabular}{|c|c|c|c|}
\hline $\begin{array}{l}\text { Technique } \\
\text { used }\end{array}$ & $\begin{array}{l}\text { Actors involved } \\
\text { and location }\end{array}$ & $\begin{array}{l}\text { Period and } \\
\text { duration }\end{array}$ & Objective \\
\hline $\begin{array}{l}\text { Participant } \\
\text { observation } \\
50 \text { field } \\
\text { diaries }\end{array}$ & $\begin{array}{l}\text { - } 3 \text { field } \\
\text { researchers; } \\
\text { - MTS } \\
\text { operational } \\
\text { rooms. }\end{array}$ & $\begin{array}{l}\text { From August } \\
2017 \text { to May } \\
2018, \\
\text { every day of } \\
\text { the week at, } \\
\text { various times }\end{array}$ & $\begin{array}{l}\text { Characterizing } \\
\text { the functioning } \\
\text { of MTS observing } \\
\text { the relationships } \\
\text { of teams, } \\
\text { professionals, and } \\
\text { users. }\end{array}$ \\
\hline $\begin{array}{l}\text { Shared } \\
\text { seminar with } \\
\text { nurses }\end{array}$ & $\begin{array}{l}-3 \text { researchers } \\
-16 \text { professionals: } \\
\text { coordinators } \\
\text { of the axes and } \\
\text { rooms for adults } \\
\text { and children, } \\
\text { day laborers, on } \\
\text { duty. }\end{array}$ & $\begin{array}{l}2018 \\
01 \text { shared } \\
\text { seminar of } \\
2 \mathrm{~h} 20\end{array}$ & $\begin{array}{l}\text { Discussing } \\
\text { with nurses the } \\
\text { analytical findings } \\
\text { of field diary } \\
\text { empirical materia } \\
\text { and the seminars } \\
\text { shared with the } \\
\text { EH managers and } \\
\text { coordinators. }\end{array}$ \\
\hline
\end{tabular}

Note: MTS - Manchester Triage System; EH - Emergency Hospital.

Source: Technical-Scientific Report (2020)(7)

\section{Study setting}

The investigation was conducted in an $\mathrm{EH}$, certified as a teaching hospital, belonging to a municipal health network, which is a reference for emergency care, meeting both the spontaneous demand and the referenced by the city's SAMU (Brazilian Emergency Ambulance Service) and ECUs (Emergency Care Units). Several technological arrangements proposed by the National Hospital Care Policy of the Ministry of Health ${ }^{(12)}$, such as welcoming with risk stratification and the management of beds and care (Kanban), are implemented in this hospital.

Their choice is justified by having a MTS in operation, the technological arrangement chosen for the reflections intended in this article, given the central position of nurses in conducting it. MTS has been implemented in hospitals for eight years, and is operated in a continuous flow in three rooms with general access to adult EH (Adult ER (Emergency Room)), in a room in the pediatric $\mathrm{EH}$ and in the emergency entrances - red rooms pediatrics and adults - for users, with greater severity, who arrive brought by ambulances and SAMU.

There is a clear change recognized both by EH managers (whether those who implemented MTS, or who run EH at the time of research) and by professionals who work there. These changes are related to the internal organization of work, but which reflect on user care, whether for the length of stay or the assistance provided. Sacoman et al. (2019) ${ }^{(2)}$ describe the implementation of this system in the municipal network of hospitals. In the first analysis plan, there is a description of flows and places from the MTS implementation.

\section{Data collection and organization}

Field diaries (FD), prepared by researchers, on different days and times of the week, for almost a year, were processed and analyzed in the collective of researchers in biweekly research seminars. In a first analytical systematization, the empirical material was organized into three main blocks: the internal relations with the team; teams' relationships with users; the team's relations with hospital management. From this material, situations and reflections made by EH professionals present in FD were selected, which were returned in shared seminars (SS) with researchers, management teams and professional coordination of the hospital. New questions were raised, and the need for other meetings was raised, now with specific professional bodies ${ }^{(7)}$.

To prepare this article, the records referring to nurses and the transcription of SS with nurses related to the objective of this article were clipped from FDs.

\section{Data analysis}

For data analysis, an exhaustive reading of FD and full transcription of SS with nurses was carried out. The main clippings of the material were presented at a research seminar. After these reflections, the researchers responsible for preparing the article made a new reading and structured the analysis from two analytical levels. These analytical plans indicate the findings related to changes in nursing roles and position in labor division organization in hospitals, which may have been triggered by the MTS implementation: a) The spaces of the Manchester Triage System: flows and places and reflections; b) Manchester Triage System in action: work processes and conflict relations.

\section{RESULTS}

\section{The spaces of the Manchester Triage System: flows and places and reflections}

The reception and risk stratification processes of patients occupy different physical spaces in the EH building. All adults who arrive walking or in wheelchairs are welcomed by a nursing technician at the reception desk (so called), next to a totem pole, where they remove a password for care, after the technician's guidance. At the entrance of an adult ER, nursing technicians are there to deliver password for risk stratification and immediately 
performs a first approach. We call this professional a "human totem", because in addition to delivering the password, it guides users; when identifying the severity, it puts a patient in priority for risk stratification, sometimes even leading him to the risk stratification room. The situation below, registered in one of FD, indicates the dynamics that occurred in that space.

[...] I stay at the reception desk with the nursing technician [...], who says that many people who arrive for consultation did not need to go to an ER, there are people who should go to BHU. ID card? He talks about the panels and tells me: they don't understand the panel, many lose their turn and come back here [...]. The entrance of people does not stop. It also gives information to those who are lost. (FD)

Next to the adult ER reception desk there is a waiting room for users who are waiting for an orthopedics consultation, where there is no risk stratification, and another for all other clinical specialties. When observing this space, it is easy to understand the reasons that lead users to miss their call. It is visible, and the nurse talks about panels in the waiting room, because"(...) users do not always understand, some cannot read, and the location does not help".

The risk stratification work takes place:

[...] in a small room, [open door], but like all the necessary equipment, with no place for the companion. When he is present, he stands. With each command on the computer, which corresponds to an answer "of a question in the protocol, another page opens, everything is computerized, and the nurse quickly makes the stratification. The questions are standard, but the singularities emerge, and the protocol, even if for a second, is left out", but I am impressed by the nurses' discipline. (FD)

Even patients who come walking can be stratified as high risk, and sent directly to the red room. In this case, stratification nurses take patients, in a wheelchair, to the red room, where the "case" passes and "delivers" them quickly to the red room nurse.

When talking about places and flows, it is evident how much MTS, a technological arrangement of care related to access with priority for the most severely ill patients, in a process of rationalization of entry, influences the organization of spaces and places and work processes to "inside" EH. That is, after the MTS implementation, EH was organized by axes related to colors, which express the clinical severity of the cases. In this way, the rooms start to receive their denomination by the degree of gravity - observation room of the green axis, yellow room and red room, for organization. Each axis has its professionals defined, i.e., nurses, nursing technicians, physicians and social workers. The physical space is searched as a place to take care of the most serious, the least serious, according to their times and needs. Multidisciplinary team professionals move along the axes. It is from this observation, both observed and reported by nurses, that they consider that it is no longer possible to think about $\mathrm{EH}$ without risk stratification. For them, this was an important gain for nurses' work, but mainly for patient care, expressed more than once by the statement "no patient is lost". We can, therefore, consider that:

[...] we have definite flows, but they cross each other all the time: there are people who enter the red room, but it is green, there are those who walk around, but the case is critical, yellow or red, and there are still those that complicate or come out of the crisis during the stay. The space is insufficient, and it is not linear. There is tension, we even discussed it, but in the end, we found a solution [...] (FD).

In summary, it was possible to observe how an arrangement of "door" reorganizes care, its places, flows and professionals, as recorded by one of the researchers in her FD.

It is clear that the flow was an achievement, a work, an "art", carried out by nurses and their team. They know what is at stake, even living with a space that is not as scanned and smooth as paper, the design of flows, can make us suppose. They argue and defend the flows, they are aware that the colors of the "stratification" are more nuanced, that the borders are blurred all the time, as they have no doubt how much this organization helped the care provided to patients in the ER. (FD)

\section{Manchester Triage System in action: work processes and conflict relations}

In the first visits to the field, it was possible to observe that nurses did not hide the strategic importance of MTS. As already mentioned, it is the protocols that help to determine patient flows, giving nurses the security and support for making decisions regarding their entry into the service, even though this often happens in a work atmosphere with interpellation and questioning by the health team, including physicians, users and companions. A nurse says that:

[...] Manchester gave nurses a little autonomy and support with regard to the patient's entry into the service. Because until then a screening was done and this was done by a nursing technician. However, this was often questioned by the medical team and they, who were in the middle of detecting where this patient was going. [...] that flow exists, the nurse will follow and the physician will have to follow and accept it. So, it gave a little support [...], especially for the nurse who is on the front line. (SS one of the nurses)

Being at the forefront does not happen without difficulties. The rear must be ensured by preconditions that, depending on the flow, must be accepted, respected and followed. Protocols and care flows of technical and technological entities are transformed into normative entities, with an intrinsic rationality that combines management with professionalism, but which stipulates the provisional suspension of the definition of the range of autonomy of each profession involved in the health team, which may have a little more or a little less autonomy, as long as you take care of the patient in a timely manner and according to the severity of the situation.

Representations about their autonomy are perceived in nurses' statements, which are structured around management pressures and professional tensions that cross their daily work and in the relationship with which conflicts arise.

Stratification nurses' work is insane: regulated, mechanized, timed, parameterized. The working hours are long. The [...] conflicts with physicians [disagreement with the stratification, centrally] have already been reported by other researchers and pointed out in other studies, but, according to them, everything seems to be resolved 
well with conversation. Patients often give different information about their symptoms to the physician and nurse, and that would be one of the bases of the conflict. (FD)

Nurses reflect on their new role with MTS, and say how they understand the reasons for the questions:

[...] in fact, in Manchester, it is the nurse who has power, who defines where the patient, when he enters, where he goes, how he will receive care, what specialty he will receive. We have conflicts with everyone, with reception, with the guard, with nursing, with social work. Because we stratify according to the complaint that the patient is bringing. And, most of the time, they [users] don't agree, because they already understand the priority. If I am stratified as green, I know it will take time. So, each one will say that the situation is the worst. [...]. So, we have this conflict. We stop and determine whether the patient will enter with a companion or not. And we are assessing the patient, seeing if he can walk, being able to talk, if all the information is given. [...] so, it is a conflict that we have with all areas. And with the physician it's no different. (SS - nurse)

This statement shows that stratification nurses' autonomy is very variable in scope, as it does not depend only on the clinical priority attributed to the stratified patients (perceptible by the color of the bracelet) and the referrals that follow (as recommended in MTS). This autonomy ends up being subjected to a chain of successive reassessments, confirming or not the stratification performed, in which the professional tensions of care management are played. The repeated situations of questioning the stratification of risk and the definition of the priority of care suggest that the professional autonomy of nurses who operate MTS is always in production, gaining greater or less elasticity when placed in relation to other professional autonomies ${ }^{(13)}$. That is, the fulfillment of all the technical procedures provided for does not necessarily reduce the conflict relations, which unfold in the relations between the different professions and professional categories involved in EH health teams. Mitigating conflict relations is not the goal of MTS, although it could be an expected indirect result given the protocolization of clinical decisions and workflows.

[...] if we stratify for a specialty or a priority stratification that the physician does not agree with [there have already been several cases], the physician says to go back to the stratification and says "you can do another stratification, because this case is not so, or not, another stratification because it is not door, is red". And it goes against our stratification that follows this protocol. And we also had [conflicts] with our own team. [...] then they themselves question the flow: why are they bringing this patient? We look at the patient, if we were not to follow the Manchester protocol, we also agree that he is a patient in red. But it is the flow. According to the protocol, we cannot deny it. Then we start with the conflict, no, this patient is not from here, he is not like that. So, the conflict is in all sectors, with all classes, with all specialties. (SS - nurses)

But the most frequent conflicts reported by nurses refer to the questions posed by physicians regarding their clinical decision, feeling obliged, before them, to detail patients' complaints to justify the stratification attributed:
Often [physicians] do not accept Manchester's stratification. [...] so, there is a lot of conflict with physicians [...]. They don't accept what we put. (SS - nurses)

Another observation brings the reflection of nurses in the stratification work and their relationship with physicians in the face of a clinical decision.

[...] there is a physician who is open to hearing our clinical opinion. There is a physician who does not accept it. I see this a lot with Manchester, [and exemplify] [...]. with Glasgow very low for the patient who entered the emergency room and [nurse] says, team, already separate something for intubation because I think we will have to intubate this patient. Then the physician didn't like it and said: are you a physician? Why do you say if you intubate the patient or not? But it was a very low Glasgow, far below what we normally see. But are you a physician? How do you say you're going to intubate? But l am seeing the patient demoted. [...] afterwards, he ended up intubating the patient. (SS - nurse)

When this happens, the protocol assures them of decisionmaking, because, even in conflict, the final word often ends up being nurses.' But this is not always the case, and, as seen above, there are many examples in which the knowledge that underlies the clinical decision of nurses who make the stratification, of a predominantly protocol nature, in which technicality tends to override indeterminacy, are subjected to scrutiny of medical knowledge as dominant knowledge-power in hospital work division.

Conflicts also arise when the stratification process is faced with management pressures. The work is constantly audited by the teams that make up the local and external MTS. This occurs, either by direct observation, or by crossing the secondary data produced in the service, from the control of the records in the system, making it difficult to leave the protocol, even if the risk situations of patients require.

Although the work seems mechanized and controlled, these nurses are faced with unpredictable cases to which the protocols are unable to respond. The report of an observation made in an adult risk stratification room is elucidative in this regard:

[an adolescent enters the risk stratification room, accompanied by his mother]. The nurse asked what the complaint was and the mother said that the boy had a memory problem, had been on treatment since he was a child, but now he was refusing to take the medication. He had been missing from home for a month [...]. I had stayed on the streets in São Paulo. She said that the social worker had stopped by her house and was instructed to look for an ER. The nurse asked what was the complaint, being told that he had been beaten by the police.

- But where is it hurt? - insisted the nurse.

- I don't know, in the foot. It was the social worker who ordered her to come. [...]

The nurse [...] did not know how to register, it seemed that the protocol at that time was not helping. [...] the mother said she had been shot years ago. The nurse then asks if the boy used drugs and he said yes. 
The nurse [...] said they were going to see a physician, put on the green bracelet and asked them to wait in the waiting room [...]. Then he turned to me and said - "What to do in this situation"? The protocol didn't really handle this case [...] what to do? Then he got up, took the boy's file and went to the next room to comment with his co-worker. (FD)

The stratification work also depends on the information given by the patient and the relationship that is established between the patient and the professional. This means that nurses' judgment involves greater complexity and differentiation than just the computerized record of symptoms. In addition to users' reports, nurses use their perception, and often there are tensions between nurses' experiences and the manifestation of signs and symptoms by users. Users learn the meaning of MTS colors and how to match these colors to waiting times. The waiting room, anteroom to the stratification room, appears as a privileged place for transmitting this and other learning, namely among patients who frequently use this service and those who are there for the first time, or even among the companions of each other, gaining particularly active ways of acting as a layperson, which has already been designated as resembling the functioning of a "network of co-workers"(14). In fact, the particularly difficult and distressing time of waiting for care becomes a time of opportunity for patients to recognize each other and their illnesses, and to share lay knowledge about professionals, the systematic of risk assessment and the possibilities of being able to circumvent the barriers and the constraints to access to care. Asked how users perceive MTS, the nurse responds:

[...] initially, there was a lot of suspicion, but today [users] accept and understand logic very well. So, I take the opportunity and ask, "In your opinion, do they already know what to say to get a stratification, where the delay is not so long?". She smiles broadly in agreement [but without judgment], and says "YES, it's not a myth, they know and teach others". (FD)

In this situation, the nurse comments how she does the clinic, outside, even following the protocol:

[...] it was of a teenager accompanied by her mother. Before entering the room, as I was at the door, I could observe his expression, which was calm, I believe he even had a slight smile on his face. When the nurse called and told her to sit down, she threw herself in the chair and started sobbing in pain, dropping some of her belongings on the floor. [...] the mother reported that she had a sore throat for a few days, she did not have a fever. The nurse was asking the necessary questions, and, at the end, she put the green ribbon on the girl's wrist, which at that time was already letting some tears roll down her face [...] she got up well, no longer in pain, and left. At the same time, the nurse said "Do you see this monitor? It is my mirror! I am starting an assessment when a patient comes down the hall." [...] he said that it is possible to see by expression, color, and other signs, not only takes into consideration what a patient says. (FD)

What is observed in these reports are expressions of the lay action of users and the nurse's work, put into action to shorten times, remove obstacles and overcome barriers that following a protocol can pose, compromising the quick access to the care sought. Nurses, without losing control of the technical tools for regulating access to care, end up taking on clinical decisions, facilitating this access to a greater or lesser extent, very rarely from a subjective position based on knowledge and personal preferences, but based on using private, tacit and informal knowledge, of an undetermined character and subtle social and cultural skills that bring them closer to users' experiences of illness. This allows them to mobilize "interpretation systems", "hunt for signs and symptoms" or "re-enter" a patient for risk stratification, which a protocol, however parameterized it may be, cannot completely remove. Two situations are very illustrative of the clinical role of nurses.

[...] the nurse I followed did not stratify blue cases because in her experience, parents do not like it and leave because it takes too long. She said that some nurses do a very large exercise "to hunt for signs and symptoms" to "increase" the degree of stratification, but she does not. (FD)

She told of a case that she suspected that the patient was having a heart attack, referred to do the electro and the result was negative. She did not comply with this result, entered the system again and took the patient inside and thus, according to her, saved her life, because he was really having a heart attack. (FD)

\section{DISCUSSION}

The results of this study show that nurses who operate MTS do not have new professional roles that prefigure in complete contrast to traditional roles. The technical content of traditional roles is renewed and restored, as it starts to incorporate technological innovation for its performance to gain more speed, efficiency, and rigor. The functional logic of organizing nursing work in an emergency service remains intact, such as welcoming patients, assessing their clinical condition and creating the conditions for the production of a more integrated and coded decision chain that allows feeding the dynamics of work in each care flow, as well as the therapeutic resolution in each patient ${ }^{(13,15)}$.

The change in content of professional roles is added to the greater stratification of nurses' positions in these services (stratifying nurses; nurse auditors of MTS; coordinating nurses of the Internal Regulation Center and the Patient Safety Center; coordinating nurses of continuing education; coordinating nurses) of the axes); however, this greater complexity of hierarchical positions does not necessarily result in a change in the structural position of nursing in the organization of hospital labor division. Although this importance is recognized in the spaces and times associated with the exclusive execution of this protocol, it is nonetheless directly monitored, controlled and audited by the management organizations of coordination and regulation of care flows ${ }^{(13,15)}$.

MTS nurses narrate repeated conflict relations that erupt in the daily work processes in which they are involved, when subjected to the combined effect of management pressures and professional tensions, especially with regard to disagreements in the stratification of patients' risk and respective color assignments of bracelets and flow ordering. It is a constant exercise of justifying the judgment produced, involving successive ratifications and 
reassessments, in relation to stratification co-workers, nurse auditors and flow control, physicians, companions and users, considering their high expectations of care ${ }^{(16)}$.

Therefore, these nurses are unable to control the boundaries of their professional autonomy, because this autonomy gains variable amplitudes, with partial status, when placed in relation to that of other professionals, according to transformations of care processes. What the results of this study showed us is that renewal and restoration of professional roles in work processes of MTS do not point to significant changes in their professional practices. They only point to functional changes, in which the dimensions of practicality/technicality occupy an immense space of intervention, asphyxiating the emergence of dimensions of uncertainty and indeterminacy (therefore, not mechanized, not timed, not parameterized, not susceptible to codification), which could only be controlled, managed and regulated by nurses who, in the contexts and directly, deal with the risk stratification system.

In this regard, some authors argue that nursing practices, in contrast to those of medicine, have shown themselves to be more open, relativistic, subject to experience, to personal interpretations and based on less codified knowledge, as an expression of a kind of indeterminacy ${ }^{(13,17)}$. Thus, the position of nursing in MTS is reduced to visible and technically readable practices, deductible from the combined exercise of management authority and medical authority.

\section{Study limitations}

Summing up the analysis questions pertinent to this study, after being properly framed in the rationalization processes that have occurred in hospital medical practices and supported by the perspectives that most directly delimited the plane of its theoretical reflection, we can point out some final considerations, provisional in time and space, and related to the conditions of a case study, but always challenging and instigating for future research.

The study carried out did not allow definitive and definitive conclusions, although important approximations were made. Thus, it was possible to envision the possible emergence of new conflicts between nursing and medicine when medical autonomy seems to be threatened by nursing autonomy. It was already more difficult to conclude as to the strategic possibilities of emergence of forms of self-government that can transform the position of nurses in the organization of work in this technological arrangement.

There are more elements to be better explored, in new research, about the relationship with users in risk stratification, their autonomous action, also as a point that can modify and regulate their own clinical "algorithms", when using their learned knowledge in their own life experiences.

\section{Contributions to nursing, health, and public policies}

Emergency services welcome the repression of demand generated in other points of care in the health system, resulting in great dissatisfaction from users, either due to the waiting time for care or the unavailability of hospital beds for admissions, resulting in the permanence of a large number of patients, for long periods, on stretchers in the halls $s^{(7,13,15)}$.

In this setting, experimenting with new technological arrangements, in particular MTS, acquire great importance for care by improving the ability to welcome and identify risks of people who seek hospital care, improving the way patients enter a hospital. In this sense, the study presented here brings contributions to think about not only the practice of nurses and their relationship in labor social division, but mainly how much this practice and the greater autonomy of these professionals represent in gaining care for users, either by prioritizing the most serious cases or by the agility of organizing care and flows into the hospital ${ }^{(7,13,15)}$.

\section{FINAL CONSIDERATIONS}

Concerning the professional roles of nurses who operate MTS, we conclude that we cannot speak properly about the existence of new roles, but only about their renewal and restoration. The content of traditional roles has been transformed, with more technological innovation, to the greater speed required to obtain more efficiency and rigor in the work of risk assessment and stratification in an emergency service, which could feed the therapeutic decision process of a streamlined, integrated and resolutive way for users. Even with greater professional stratification, upstream and downstream of this process, this does not add new roles to traditional roles. It only represents the greater complexity of coordination and management of professional bureaucracy, in which nurses have always been traditionally present and active, if we refer to the history of the organization of the hospital and its services. Therefore, we cannot say that there is a structural change in the position of nursing in hospital labor division organization. This position continues to be maintained and reproduced, but on another scale, technical and technological, of care production.

Thus, the professional practices of nurses associated with this technological arrangement undergo changes, but almost exclusively of a functional nature and associated with the exclusive execution of this risk stratification and ordering of flows, immersed in conflict situations, both due to management pressures and the effect of professional tensions. The former ones monitor, control and audit. The latter doubt, deny and devalue. For the former, professionals performance unfolds in incessant exercises to demonstrate their good performance, their competence, their efficiency and their productivity. For the latter, their practices are developed in frequent tests of proof of nursing knowledge, technical knowledge of MTS, knowledge of the risk of disease, which go through repeating and confirming successive risk assessments and incessant justifications of the decision made regarding to the proposed referrals. Conflict relationships sometimes arise from these situations with co-workers, physicians, patients and their companions. Therefore, it can be concluded that the nature and scope of these professional practices do not change, they only increase with dimensions of effectiveness and fluidity, required by technological arrangements.

As for the professional autonomy of nurses, what can we conclude? On the one hand, that when placed in relation to the autonomies of other professionals, its borders are neither fixed nor stable, expanding or contracting according to the micropolitical changes in the governance of care. They widen substantially when 
dimensions of their practices include uncertain and indeterminate risk assessments and stratifications, which escape what is parameterized and coded. This is how more open, relativistic practices, linked to experience and personal interpretation, emerge in an unpredictable way. On the other hand, and closing the circle, we can conclude that it is in this control of the boundaries of their professional autonomy that the opportunities to transform nurses' professional practices would be based.

\section{REFERENCES}

1. Guedes HM, Souza KM, Lima PO, Martins JCA, Chianca TCM. Relação entre queixas apresentadas por pacientes na urgência e o desfecho final. Rev Latino-Am Enfermagem. 2015;23(4):587-94. doi: 10.1590/0104-1169.0227.2592

2. Sacoman TM, Beltrammi DGM, Andreazza R, Cecílio LCO, Chioro dos Reis AA. Implantação do Sistema de Classificação de Risco Manchester em uma rede municipal de urgência. Saúde Debate. 2019;43(121):354-67. doi: 10.1590/0103-1104201912105

3. Grupo Brasileiro de Classificação de Risco. Diretrizes para implementação do Sistema Manchester de Classificação de Risco nos pontos de atenção às urgências e emergências: como implementar o Sistema de Manchester de Classificação de Risco em sua instituição de saúde[Internet]. 2. ed.. Belo Horizonte: GBCR; 2015 [cited 2019 Sep 23]. [18 p.]. Available from: http://gbcr.org.br/public/uploads/ filemanager/source/54c127352e3b2.pdf

4. Chan SS, Cheung NK, Graham CA, Rainer TH. Strategies and solutions to alleviate access block and overcrowding in emergency departments. Hong Kong Med J 2015;21(4):345-52. doi: 10.12809/hkmj144399

5. Williams K. Advanced practitioners in emergency care: a literature review. Emerg Nurse 2017;25(4):36-41. doi: 10.7748/en.2017.e1685

6. Jennings N, Clifford S, Fox AR, O'Connell, Gardner G. The impact of nurse practitioner services on cost, quality of care, satisfaction and waiting times in the emergency department: a systematic review. Int J Nurs Stud 2015;52(1):421-35. doi: 10.1016/j.ijnurstu.2014.07.006

7. Andreazza R, Chioro AAR. Arranjos tecnológicos de gestão do cuidado em um Hospital de Pronto Socorro: relatório técnico-científico final. 2020. doi: 10.13140/RG.2.2.10369.81765

8. Caprara A, Landim LP. Etnografia: usos, potencialidades e limites na pesquisa em saúde. Interface Comun Saúde Educ. 2008;12(25):363-76. doi: 10.1590/S1414-32832008000200011

9. Strauss AL, Fagerhaugh SY, Suczek B, Wiener C. The Social organization of Medical Work. Routledge, 1985. 120p.

10. Freidson E. Professional dominance: the social structure of Medical Care. New York: Atherton Press, 1970. 242p.

11. Poupart J, Deslauries JP, Groulx AL, Mayer R, Pires A. A pesquisa qualitativa: enfoques epistemológicos e metodológicos. Petrópolis: Vozes; 2016. 464p.

12. Ministério da Saúde (BR). Portaria GM/MS 2.395 de 11/10/2011. Organiza o Componente Hospitalar da Rede de Atenção às Urgências no âmbito do Sistema Único de Saúde (SUS) [Internet]. 2011 [cited 2020 Jun 20] Available from: http://bvsms.saude.gov.br/bvs/saudelegis/ gm/2011/prt2395_11_10_2011.html

13. Cecilio LCO, Chioro dos Reis AA, Andreazza R, Spedo SM, Cruz NLM, Carapinheiro G, et al. Enfermeiros na operacionalização do Kanban: novos sentidos para a prática profissional em contexto hospitalar? Ciênc Saúde Coletiva. 2020;25:283-92. doi: $10.1590 / 1413-81232020251.28362019$

14. Cecilio LCO, Carapinheiro G, Andreazza R. O agir leigo e o cuidado em saúde: a produção de mapas de cuidado. Cad Saúde Pública. 2014;30(7):1502-14. doi: 10.1590/0102-311X00055913

15. Cecilio LCO, Chioro dos Reis AA, Correa T, Carapinheiro G, Andreazza R, Cruz NLM, et al. Os médicos e a gestão do cuidado em serviços hospitalares de emergência: poder profissional ameaçado? Cad Saúde Pública. 2020;6(3):e0024291. doi: 10.1590/0102-31100242918

16. Cecílio LCO, Moreira ME. Disputa de interesses, mecanismos de controle e conflitos: a trama de poder nas organizações de saúde. RAP[Internet]2002 [cited 2020 Jun 22];36(4):587-608.Available from: http://bibliotecadigital.fgv.br/ojs/index.php/rap/article/ view/6454/5038

17. Meleis A. Theoretical nursing: development and progress, Philadelphia: J B Lippincott and Co. 1985. 74p. 